\title{
Regular las emociones: Biopolítica y educación emocional *
}

\author{
Regulate emotions: Biopolitics and emotional education
}

\author{
Por: Alegre, Daniel Andrés* \\ Universidad Nacional del Nordeste. \\ E-mail: andresalegre@outlook.com
}

Fecha de recepción: 15/03/2021

Fecha de aprobación: 01/04/2021

DOI: http://dx.doi.org/10.30972/ach.065599

\section{Resumen}

En el contexto actual de avances a nivel mundial de gobiernos neoliberales que buscan imponer sus lógicas en todos los ámbitos de lo público, se torna necesario emplear herramientas teóricas que nos permitan oponer resistencias a esos intentos de captura. En este sentido, este texto analiza la propuesta pedagógica denominada educación emocional impulsada por distintas instituciones y partidos de diversos signos políticos en Argentina y el mundo. Para ello se emplean categorías propuestas por Michel Foucault en sus cursos del Collège de France, especialmente las ligadas al concepto de Biopolítica, como son: población, seguridad, gobierno, etc. El objetivo de este texto es situar a la educación emocional como uno de los dispositivos de seguridad descritos por el filósofo francés en tanto que tiene como finalidad producir sujetos-ciudadanos autorregulados y emocionalmente competentes que no representen riesgos ni amenazas, es decir, que sean productivos.

Palabras claves: biopolítica; seguridad; gobierno; educación emocional; giro afectivo.

\section{Abstract}

\footnotetext{
* El presente trabajo fue realizado en el contexto del Seminario II: Análisis de un problema filosófico.

* Estudiante de la Licenciatura en Filosofía de la Facultad de Humanidades (UNNE).
} 
In the current context of global advances of neoliberal governments that seek to impose their logic in all public spheres, it is necessary to use theoretical tools that allow us to resist these capture attempts. In this sense, this text analyzes the pedagogical proposal called emotional education promoted by different institutions and parties of various political signs in Argentina and the world. For this, categories proposed by Michel Foucault in his courses at the Collège de France are used, especially those linked to the concept of biopolitics, such as: population, security, government, etc. The aim of this text is to place emotional education as one of the security devices described by the French philosopher as its purpose is to produce selfregulated and emotional competent subjects-citizens that do not represent risks or threats, that is, that are productive.

Key words: biopolitics; security; government; emotional education; affective turn.

\section{Cómo citar este artículo:}

APA: Alegre, D. A. (2021). Regular las emociones: Biopolítica y educación emocional. Acheronta, № 6, 1-26. Recuperado de: (agregar dirección web)

\section{Introducción}

En el año 2016 se aprobó en la provincia de Corrientes la Ley Provincial Nº 6.398 de Educación Emocional. En su artículo $3^{\circ}$ se establecen como fines y objetivos de la misma "desarrollar, mediante la enseñanza formal, cada una de las habilidades emocionales-conocimiento de uno mismo, autorregulación emocional, motivación o aprovechamiento productivo de las emociones, empatía y habilidades sociales- así como las habilidades de elección en cada niña y niño y tutores/as -docentes y padresmediante la Educación Emocional, con el objetivo de alcanzar una mejor calidad de vida de todos los ciudadanos".

De esta manera nociones como autoconocimiento, autorregulación y aprovechamiento productivo, asociadas a otras como "calidad de vida de todos los ciudadanos", hicieron su ingreso por la puerta grande de la educación pública sin un aparato crítico que le oponga ninguna resistencia. Mediante la caja de herramientas 
que nos ofrece Michel Foucault al reflexionar sobre el surgimiento de la noción de gobierno y la constitución de un sujeto/población objeto de políticas gubernamentales, nos proponemos analizar algunos preceptos de la versión argentina de la Educación Emocional y de sus expresiones en el contexto anglosajón, del cual esta ley es una adopción acrítica.

El escrito recorre principalmente la evolución conceptual de los cursos de Foucault dictados en los periodos de 1975-1976 y 1977-1978. De esta forma en un primer momento se desarrolla el surgimiento de la biopolítica en oposición al poder soberano, para luego abordar las cuatro características generales de los dispositivos de seguridad. Seguidamente se analiza el gobierno como problema técnico-político para finalizar describiendo críticamente las características de la educación emocional y las razones que nos permiten colocarla en el conjunto de dispositivos biopolíticos de seguridad.

\section{Poder soberano y Biopoder}

En su curso Defender la sociedad Michel Foucault expone la teoría clásica de la soberanía, según la cual se concibe al poder soberano como el poder de vida y de muerte, es decir, la capacidad de hacer morir y dejar vivir. De esta consideración se desprenden dos consecuencias, una teórica y otra práctica. Por un lado, el ámbito de la vida y la muerte no son considerados esferas independientes del poder político sino como fundamentalmente atravesadas por este, por otro lado, esta situación genera en lo práctico un desequilibrio: el soberano puede hacer morir pero, en cuanto a la vida, solo puede replegarse en un no hacer. El poder soberano está del lado de la muerte, el poder de matar es la única vía, indirecta, por la cual ejercer el derecho de vida (Foucault, 2006a).

Entre los siglos XVIII y XIX se introduce un tipo de poder destinado a subsanar este desequilibrio fundante del poder soberano, un poder que se despliega sobre el campo de la vida y hace vivir. Ya durante los siglos XVII y XVIII los debates de los juristas daban cuenta del problema del estatus del poder de muerte ya que la protección de la vida era el motivo fundante del poder soberano, y por ello el poder de 
quitársela a los súbditos carecería de legitimidad. No obstante, no es sino hasta el siglo XIX que la cuestión de la vida entra en el horizonte del poder político.

Esta nueva forma de poder se diferencia no sólo del poder soberano, sino también de la disciplina, serie de tecnologías dispuesta para crear todo un campo de visibilidad basadas en el principio económico del acrecentamiento de fuerzas con el menor gasto posible. La nueva forma de gobernar que se introduce a mediados del siglo XVIII es de otro nivel, ya no individualizador sino masificador, que toma al hombre no en su corporalidad individualizada, sino que se encarga de los procesos vitales de los hombres en conjunto (fenómenos de la especie tales como los nacimientos, las muertes, la producción, las enfermedades, etc.) y los transforma en fenómenos de población como la natalidad, la mortalidad, la morbilidad, etc. En este sentido, si al poder disciplinario le correspondía una anatomopolítica preocupada por la segmentación y control del cuerpo individual, esta nueva forma de gobierno que Foucault llama biopolítica se interesa por el cuerpo/especie, cuerpo colectivo de la población.

De este modo surge a la política un nuevo sujeto político que ya no es el individuo libremente asociado para constituir al soberano, ni tampoco es el cuerpo individual sometido a prácticas de control y disciplinamiento, en este caso surge la población como objeto alrededor del cual se debe construir un campo de saber para su administración. El cuerpo/población, en palabras de Foucault (2006a) consiste en "un nuevo cuerpo: cuerpo múltiple, cuerpo de muchas cabezas, si no infinito, al menos necesariamente innumerable" que se constituye en "problema a la vez científico y político, como problema biológico y problema de poder" (p.222).

Los fenómenos observados por el biopoder incumben no solo a la vida particular sino también a la vida colectiva de la población. Tomados desde el punto de vista del individuo estos fenómenos son aleatorios, impredecibles, inabordables por la política o la economía, en cambio, tomados desde lo que hay en ellos de colectivo, constante, durable, serial, etc. pueden ser objeto de medición, se vuelven objetos de interés para la política y la economía. Por ello se diferencian de los mecanismos disciplinarios, estos consideran la individualidad de los cuerpos para así controlarlos 
mejor, en cambio en el caso de los mecanismos biopolíticos el fin último es el de la regularización.

Se trata, sobre todo, de establecer mecanismos reguladores que, en esa población global con su campo aleatorio, puedan fijar un equilibrio, mantener un promedio, establecer una especie de homeostasis, asegurar compensaciones; en síntesis, de instalar mecanismos de seguridad alrededor de ese carácter aleatorio que es inherente a una población de seres vivos; optimizar, si ustedes quieren, un estado de vida: mecanismos, podrán advertirlo, como los disciplinarios, destinados en suma a maximizar fuerzas y a extraerlas, pero que recorren caminos enteramente diferentes (Foucault, 2006a: 223).

Tenemos entonces dos conjuntos de mecanismos políticos que operan en distintos niveles para compensar el desequilibrio del poder soberano que lo hacía deficiente: el conjunto de tecnologías disciplinarias centradas en producir efectos individualizadores, en producir cuerpos dóciles, y las tecnologías regularizadoras interesadas en insertar ese cuerpo individualizado en un conjunto más amplio de fenómenos para así gestionarlos mejor. Estos dos conjuntos no se excluyen sino que están dispuestos de forma perpendicular, son dos planos que al entrecruzarse vuelven observable una serie de fenómenos que participan de ambas series de tecnologías y son efectos de ambos mecanismos.

La sexualidad es uno de estos fenómenos duales que captan el interés del filósofo francés, en tanto que es objeto de la disciplina por su subordinación a fines reproductivos y al mismo tiempo de la regularización, ya que una sexualidad "desviada" afectará la calidad de vida no sólo del individuo sino también la de las futuras generaciones (teoría de la degeneración). De este modo, el hecho de que la sexualidad esté "en la encrucijada entre el cuerpo y la población" (Foucault, 2006a: 227) pone de relieve que el biopoder no sólo tiene como objetivo "realzar la vida, controlar sus accidentes, sus riesgos, sus deficiencias" (p.224) sino también el de normalizar los fenómenos poblacionales para ponerlos al servicio de un poder productivo. 
Abril 2021.

ISSN 2344-9934

La pregunta formulada por Foucault para pensar estos niveles de poder es ¿qué tienen en común estas dos series de tecnologías que les permite complementarse para un mejor empleo de los cuerpos? Respecto de esto señala que:

El elemento que va a circular de lo disciplinario a lo regularizador, que va a aplicarse del mismo modo al cuerpo y a la población, que permite a la vez controlar el orden disciplinario del cuerpo y los acontecimientos aleatorios de una multiplicidad biológica, el elemento que circula de uno a la otra, es la norma (Foucault, 2006a: 229).

Es así que una sociedad en la que se ejerce el poder disciplinario y el poder regulador está atravesada en ambos planos por mecanismos de normalización. Mediante estos se determina lo normal mediante la exclusión de lo anormal, y sólo así en última instancia se vuelve legítimo el ejercicio del poder de muerte. Con este propósito los mecanismos biopolíticos se encargan de medir, cuantificar, delimitar las variables de riesgo y de significarlas como aquello que es necesario de ser exterminado en tanto que afecta a la calidad de vida de la población, a su prosperidad, sanidad, pureza, etc. De esta forma, el riesgo biológico se vuelve pasible, cuando no de muerte física, al menos de una muerte política, rechazo, expulsión, etc.

Foucault atribuye al racismo esta operación mediante la cual se legitima el ejercicio del poder de muerte, según el autor este mecanismo tiene dos momentos. En primer lugar se fragmenta el continuum biológico de la especie humana entre aquellos que deben "morir" para que otros vivan y en segundo lugar se establece una relación positivo-biológica entre la eliminación del Otro y la sanidad/higiene/pureza de unos pocos.

Lo que nos interesa resaltar es que mediante la normalización vehiculizada por mecanismos biopolíticos se opera un desplazamiento en la lógica de la guerra por móviles abiertamente políticos hacia una lógica mucho más subrepticia, la de la seguridad, según la cual existen peligros que deben ser controlados y que la población deber ser asegurada:

Si ese mecanismo puede actuar, es porque los enemigos que interesa suprimir no son los adversarios en el sentido político del término; son los peligros, externos o internos, con respecto a la población y para la población. En otras palabras, la 
muerte, el imperativo de muerte, sólo es admisible en el sistema de biopoder si no tiende a la victoria sobre los adversarios políticos sino a la eliminación del peligro biológico y al fortalecimiento, directamente ligado a esa eliminación (Foucault, 2006a: 231).

Los mecanismos biopolíticos permiten hacer emerger el cuerpo/población a partir de la observación de los fenómenos globales de la especie, este trabajo sobre el dato durable del hombre/especie, a su vez, permite la identificación de variables de riesgo en los niveles individuales y poblacionales. El tratamiento que la sociedad de normalización le da a estos datos está marcado por la biologización y por la necesidad de la eliminación para favorecer la vida propia. De este modo, mediante la regularización se busca reducir lo probable, lo impredecible y sus posibles efectos. En última instancia, el ejercicio del biopoder tiene como objetivo reducir la anormalidad.

\section{La seguridad}

En el curso Seguridad, territorio, población de 1977-1978, Foucault realiza un ligero replanteo del esquema presentado en el apartado anterior en el que se distinguía al poder soberano del poder disciplinario y del biopoder (regularizador). En este curso le interesa abordar las convergencias de estas dos últimas series de tecnologías y una tercera serie constituida por el sistema jurídico-legal (al que antes llamara poder soberano). Estos tres conjuntos de mecanismos pueden encontrarse a través de la historia, por lo que su aparición no es de modo alguno sucesiva ni mucho menos se cancelan entre ellos. Es decir, que no deben ser pensados como eras de lo legal, de la disciplina o de la seguridad en la que una vendría a reemplazar a la anterior, sino que al menos en la época moderna los tres sistemas coexisten, si bien la historia hará variar la correlación entre ellos, lo que el autor nombra como "la dominante" (Foucault, 2006b: 23). Es decir que los tres mecanismos forman un edificio en el que el cambio viene dado por la relación de preeminencia de uno de ellos según el perfeccionamiento de las técnicas empleadas, siguiendo un principio económico de costo-beneficio (efectividad).

Foucault señala la posibilidad de que la sociedad actual se caracterice por una economía del poder dominada por los mecanismos de seguridad, es por ello que 
Abril 2021.

ISSN 2344-9934

resulta necesario analizar el modo en que estos mecanismos actúan. Los tres conjuntos de mecanismos tienen en común el hecho de que trabajan sobre la multiplicidad, de la población en el caso del sistema legal/jurídico, y es la multiplicidad lo que debe ser reducida mediante la organización, control, jerarquización, etc. en el caso de la disciplina. En los límites de este trabajo nos interesa señalar el modo en que los mecanismos de seguridad manejan la multiplicidad, el autor señala al menos cuatro rasgos generales que pueden ser pensados como rutas exploratorias: $a$ ) los espacios de seguridad, b) el tratamiento de lo aleatorio, c) formas específicas de normalización de la seguridad y $d$ ) las técnicas que modelan la población.

a) Respecto del tratamiento que la seguridad hace de los espacios podríamos decir que el principal problema al que se enfrenta es el de la gestión de la circulación: “...se trataba de organizar la circulación, suprimir los aspectos peligrosos, distinguir entre la buena y la mala circulación, maximizar la primera y reducir la segunda" (Foucault, 2006b: 38). El problema del espacio se resume en la necesidad de regular/optimizar la circulación de órdenes políticas, de ideas y mercancías. Una nota característica que Foucault percibe en el tratamiento de la seguridad respecto del ordenamiento de la ciudad ideal es la transformación del espacio en medio, es decir, en herramienta explicativa (en sentido de causa-efecto) de las interacciones mutuas entre lo natural y lo artificial, entre la geografía y las conductas humanas.

b) Por parte del tratamiento de lo aleatorio, lo que Foucault Ilama "el acontecimiento", los dispositivos de seguridad tomarán tres vías. En primer lugar, adoptan una tendencia constante a integrar circuitos de fenómenos cada vez más grandes, para intervenir en una realidad se buscará entenderla a partir de un marco ampliado de análisis (incluyendo la política, economía, psicología, física, etc.) y se intentará dilucidar las relaciones entre los componentes de los fenómenos. En segundo lugar, la seguridad esencialmente deja hacer, es decir, toma al fenómeno regulado en su propia naturaleza, se apoya en sus detalles (su particularidad): "la función de la seguridad consiste en apoyarse en los detalles, no valorados en sí mismos como bien o mal y tomados en cambio como procesos necesarios e inevitables, procesos de la naturaleza en sentido lato" (Foucault, 2006b: 7). Para poder hacer posible esta 
naturalización del fenómeno, esta toma de distancia de las valoraciones, los dispositivos realizan una escisión fundamental entre lo que incumbe a los individuos y lo que incumbe a la población, naturalmente, el dispositivo de seguridad accionará en el segundo nivel, el individual sólo será considerado instrumentalmente en tanto que afecte a la población:

[El nivel individual] no será pertinente, o mejor, sólo lo será en cuanto, manejado como es debido, mantenido como es debido, alentado como corresponde, permita lo que se procura en el nivel que sí es pertinente (...) La población es pertinente como objetivo y los individuos (...) lo serán sencillamente como instrumento, relevo o condición para obtener algo en el plano de la población (Foucault, 2006b: 63).

Por último, a diferencia de los dispositivos legal y disciplinario que hacen uso de la prohibición y prescripción respectivamente, el dispositivo de seguridad regula gracias a que se posiciona en un punto (la población) desde donde "las cosas van a producirse, sean deseables o indeseables" (p.68). Es decir, apoyada en la "realidad" del fenómeno, sus detalles, la regulación hace interactuar los elementos de esa realidad, los pone en relación recíproca para anular, limitar, frenar, etc. esto o aquello.

c) El tercer rasgo general de los mecanismos de seguridad es la normalización. En este punto hay una radical diferencia respecto de la disciplina, ya que en esta se lleva a cabo una normación, es decir, una adaptación de los cuerpos, gestos y actos a un modelo construido a partir de la esperada obtención de ciertos resultados. Así planteada, en la disciplina tiene primacía la norma, con ella como horizonte prescriptivo se buscará lo normal. En cambio, en la seguridad ocurre que se busca establecer las curvas de normalidad, es decir, señalar lo normal y lo "anormal" como dos puntos de un espectro pero haciendo que estos dos interactúen entre sí para que se asimilen: "la operación de normalización consistirá en hacer interactuar esas diferentes atribuciones de normalidad y procurar que las más desfavorables se asimilen a las más favorables" (Foucault, 2006b: 83). A partir del estudio de las normalidades se deduce un "juego de distribuciones" valoradas como más o menos favorables, el cual se tomará como norma. Es decir, en la seguridad lo normal es anterior a la norma, es un efecto de las técnicas poblacionales. 
La determinación de lo normal es posible gracias al cálculo estadístico, esta técnica permitió perfeccionar los mecanismos de vigilancia ya no a nivel individual (disciplinario) sino a nivel de la población. Esta vigilancia poblacional adopta la forma de cálculo de costo respecto de un posible beneficio, como en el caso de la determinación de los sectores sociales que deben ser inoculados contra la viruela para reducir la morbilidad. De este modo surge la noción de caso en detrimento de la idea de enfermedad reinante (asociada a un medio, clase social, clima, etc.): “[el caso] es una manera de individualizar el fenómeno colectivo de la enfermedad o de colectivizar, pero según la modalidad de la cuantificación y de lo racional e identificable, los fenómenos individuales, para integrarlos a un campo colectivo" (Foucault, 2006b: 80). A partir de esta técnica matemático-política es posible la división de la población según criterios estadísticos y la determinación de los factores de riesgo o de probabilidades que "el acontecimiento" (lo aleatorio) tome lugar. Es decir, también aparece la noción de peligro, ya que se hace posible la identificación de las características "peligrosas" que señalarían riesgos diferenciales para cada división hecha mediante el método estadístico.

d) El último rasgo general de los mecanismos de seguridad es el ya mencionado surgimiento de un nuevo sujeto político: la población. Este surgimiento no sucede sino a partir de determinadas técnicas y nociones que vieron la luz a mediados del siglo XVIII. Foucault (2006b) señala que la discusión pública sobre la política económica acaecida en ese periodo entre mercantilistas y fisiócratas deja entrever una serie de consecuencias filosóficas y prácticas en lo que refiere a técnicas de gobierno. Según el autor, la concepción de población de los mercantilistas se ajusta al modelo soberanosúbditos, para ellos la población es principio de riqueza y fuerza productiva sobre las que se puede intervenir con la fuerza del imperium por medio de leyes, reglamentos, edictos, etc. En cambio, los fisiócratas ven a la población como "un conjunto de procesos que es menester manejar en sus aspectos naturales y a partir de ellos" (p.93). Es interesante analizar en qué consiste esta idea de naturalidad porque por un lado es indicativo de la presencia de un mecanismo biopolítico de seguridad, y además porque 
es aquí donde se vuelve observable el modo de pensar la interacción entre las técnicas y el moldeado/surgimiento de la población.

La naturalidad presente en la idea de población de los fisiócratas consta de tres características: está sujeta a variables, incluye el factor individual (deseo) y atiende a la regularidad de los fenómenos. Primero, "la población tal como se la problematiza en el pensamiento, pero también en la práctica gubernamental del siglo XVIII, no es la simple suma de los individuos que habitan un territorio (...) de hecho, la población no es un dato básico" (Foucault, 2006b: 93). Lo que aquí se entiende por población no es un dato que se halle en la naturaleza, sino que es efecto de tecnologías de poder, se encuentra en la intersección de múltiples variables: territorio, clima, comercio, circulación de riquezas, costumbres, leyes, valores morales, etc. Esto implica que la relación entre la voluntad del soberano y las conductas de los súbditos ya no es transparente, pero aún es accesible al poder por vías indirectas: "[la nueva técnica consiste en] influir sobre las cosas alejadas de la población, pero que según hacen saber el cálculo, el análisis y la reflexión, pueden actuar en concreto sobre ella" (p.95). Es por ello que el reinado se transforma en gobierno. Segundo, la población está compuesta por individuos cuyos comportamientos en cierta medida son imprevisibles, pero el motor de dicho comportamiento es el deseo por el interés personal, la seguridad se encargará de decirle sí a los deseos individuales ya que la búsqueda del interés personal redundará siempre en interés colectivo. El deseo será a la vez librado a la espontaneidad y regulado, por lo que su naturalidad tiene un doble estatus. Tercero, tantos las variables a las que está sujeta la población como la espontaneidad del deseo individual son fenómenos que a nivel individual son irregulares, pero tomadas a un nivel colectivo estos accidentes se tornan en regularidad aprehensibles estadísticamente. Es decir que la técnica biopolítica encuentra regularidades hasta en los accidentes. Según estas tres modulaciones entre técnicas y naturalidad es evidente que la naturaleza ya no es ajena al ámbito del poder:

No está la naturaleza y luego, por encima de ella o contra ella el soberano y la relación de obediencia que se le debe. Hay una población cuya naturaleza es tal que dentro y con ayuda de esta, así como con referencia a ella, el soberano debe desplegar procedimientos meditados de gobierno (Foucault, 2006b: 100-101). 
En suma, frente a las deficiencias de un poder soberano que sólo puede actuar desde la negatividad, la prohibición, la muerte, se erigen los poderes disciplinarios y regularizadores. El primero apunta a la producción de individualidades mediante una serie de prescripciones con sus castigos y su necesario control, el segundo, analizado aquí en extenso, se preocupa por hacer ingresar la vida al campo de acción política a través de la determinación de regularidades que servirán como normas a las que se debe alcanzar por vías indirectas, mediante un juego de encauzamientos, manejos, estímulos, en última instancia, mediante el gobierno de la población.

El poder regularizador vehiculizado por mecanismos de seguridad permite lidiar con las multiplicidades y sus avatares. Por la vía positiva, permite prever las eventualidades, conducirlas, darle curso, y así anularlas. De este modo busca asegurar el gobierno asegurando a la población, su cometido es netamente político, busca disipar el riesgo interno a la población, lo que responde a una serie particular de necesidades políticas y económicas.

Hasta aquí el problema del gobierno planteado a partir de la población, de las grandes masas de individuos, el problema de un poder despersonalizado y colectivizante. ¿Cómo es posible, entonces, la presencia paradójica, en el mundo occidental, de una noción de gobierno de los individuos coexistiendo con el de la población? Foucault rastrea dos nociones para explicar la posibilidad de gobierno de la población y del individuo al mismo tiempo. Por un lado el gobierno pastoral y el gobierno de las almas. Estas dos nociones tienen su origen en el oriente mediterráneo, allí se entendía al soberano como un pastor, como aquel que conoce los mejores caminos por dónde guiar a las ovejas, el pueblo, y que en última instancia es un delegado del pastor supremo, Dios. Es por ello que se concibe a la pastoral como un gobierno de masas en movimiento, como la guía de un punto a otro. Esto se opone a las nociones griegas de deidad, ya que estos no pensaban a sus dioses solamente como benevolentes, sino como irascibles, vengativos, indiferentes, etc., en cambio la pastoral trasluce esa idea de benevolencia absoluta. En cuanto al gobierno de las almas, existe una paradoja de la pastoral, en la que el gobierno debe ser sobre el rebaño, pero también sobre cada oveja, omnes et singulatim, debe tener los ojos 
puestos sobre todos y cada uno a la vez. Es a esta paradoja a la que intentarán responder las tecnologías de poder (Foucault, 2008a).

Tanto la tradición griega como la pastoral cristiana tendrán en común que al plantear el problema del gobierno lo harán en clave moral. Es así que el gobierno por excelencia será el gobierno de sí en términos de la constitución del sí mismo en sujeto moral. Foucault señala que los sistemas morales siguen un modelo jurídico/disciplinario, basado en el código y las infracciones, o bien pueden centrarse en las prácticas de sí, es decir, en los procesos de subjetivación que darán como resultado una especial relación con el yo, un sujeto moral (Foucault, 2008b). La reflexión sobre el "sí mismo", entonces, adopta una vertiente moral y de este modo la vigilancia sobre el sujeto, es decir, sobre el propio proceso de subjetivación, la manera de relacionarse del sujeto consigo mismo y de actuar en relación al código moral se vuelve pieza fundante de la seguridad.

\section{Educar las emociones}

El análisis foucaultiano de las tecnologías de regulación y del gobierno pastoral descriptas hasta aquí nos servirán como aparato crítico para abordar un fenómeno global propio de nuestros tiempos, presente fuertemente en el campo de las políticas educativas denominado Educación Emocional. Esta propuesta pedagógica, mediante la adopción de leyes en varios países incluidas varias jurisdicciones de Argentina, se transformó en una política pública en los últimos años. Mediante los conceptos de biopolítica, seguridad, gobierno y otros tantos, así como nociones formuladas en el campo de los estudio de las emociones como significado socio-culturalmente mediado, es posible situar a la educación emocional (EE) como un reciente mecanismo de normalización que retoma las discursivas preexistentes en las tradiciones pedagógicas positivistas y las adapta a las necesidades de gobierno que actualmente atraviesan los Estados que siguen políticas neoliberales. Es por ello que resulta necesario abordar críticamente los principales postulados de la EE para explicitar sus presupuestos.

A través del abordaje de la EE pretendemos establecer una relación entre la biopolítica encarnada en dispositivos de seguridad/regularización y este dispositivo 
Abril 2021.

ISSN 2344-9934

pedagógico. La hipótesis que guía esta exploración es que la educación emocional no es una propuesta pedagógica más entre otras, sino que participa de lo que algunas autoras han denominado privatización de la educación (Sorondo, 2019), esto es, la adopción por parte del sector educativo público de principios, procedimientos y lógicas discursivas propias del sector empresarial. Esta tendencia, en nuestra opinión, se encuadra en un rasgo propio de la etapa actual del capitalismo tardío tal como lo entiende Fisher (2016) según el cual los fenómenos psicofísicos, entre los cuales se pueden incluir ciertas emociones, se privatizan, es decir, son aislados de sus causas sociopolíticas, individualizando e interiorizando las causas de todo descontento: "la privatización del estrés ha sido una parte central del proyecto cuya meta principal fue la destrucción del concepto de lo público, ese concepto del cual depende, fundamentalmente, el confort psíquico" (Fisher, 2016: 137). Más profundamente creemos que en los presupuestos no explicitados de la EE subyace la finalidad de producción de un tipo específico de sujeto, para lo cual se sirve de mecanismos biopolíticos.

La EE es una propuesta pedagógica que hoy en día recorre el mundo, en el caso latinoamericano se han adoptado leyes y programas en Chile, Argentina y México así como en EEUU y Europa. Esta propuesta se basa en los desarrollos de Howard Gardner y su teoría de las inteligencias múltiples, según este autor la inteligencia no es un conjunto unitario, sino una red de conjuntos autónomos especializados en resolver distintos tipos de problemas (Gardner, 2016). El autor ofrece una tipología de siete inteligencias, de ellas las que aquí nos interesan son las inteligencias intra-personal e inter-personal, pues es en base a estas que Daniel Goleman (1997) propondrá el concepto de inteligencia emocional, que es en efecto la suma de las dos inteligencias descritas por Gardner. Armado con esta batería conceptual, Goleman divide la vida mental en dos "mentes": una pensante y otra sintiente. La primera, como podrá deducirse, es la encargada de las operaciones estimadas superiores asociadas al razonamiento y la toma de decisiones, mientras la segunda es impulsiva, primitiva e irracional. Ambas interactúan y conforman el sistema mental que sirve de "guía para nuestra estancia en el mundo" (Goleman, 1997: 27). La distinción entre las dos mentes 
no es gratuita, ya que siguiendo esta distinción la educación emocional alienta a identificar y expresar las emociones en el ámbito del aula, pero al mismo tiempo dispone de una serie de mecanismos para acallarlas si resultan inaceptables. La distinción entre una mente racional y otra sintiente señalaría que la razón se debe erigir por sobre la emoción si estas resultan "desadaptativas" (Abramowski, 2017).

En el ámbito nacional la EE se adoptó en algunas jurisdicciones como Corrientes y Buenos Aires, mientras que en otras, existen proyectos de leyes provinciales presentados. Lucas Malaisi, presidente de la Fundación Educación Emocional y creador del proyecto de ley nacional de EE, es el autor de textos centrales en la implementación de la propuesta en Corrientes así como uno de los representantes a nivel nacional de esta perspectiva. Según Malaisi la EE posee cinco pilares: el autoconocimiento, la autorregulación, la empatía, la motivación y las habilidades sociales. Esto es una traspolación del programa educativo que en el Reino Unido se conoce como Social and Emotional Aspecs of Learning (SEAL) dirigido a escuelas emplazadas en áreas marginales de las principales ciudades inglesas (Gillies, 2008).

Podrá notarse por qué nos resulta interesante analizar esta pedagogía a la luz de las nociones foucaultianas de gobierno, seguridad, biopolítica, etc. Valga de ejemplo la conceptualización de la EE que el autor nos ofrece: "la educación emocional tiene un doble objetivo: mejorar la calidad de vida de las personas y disminuir las conductas sintomáticas" (Clarín 30/10/2019) ${ }^{1}$. Según Ana Abramowski (2017) la perspectiva sobre las emociones adoptada por la EE forma parte del ingreso de la psicología positiva al campo de la educación con fines políticos muy definidos, aunque no explicitados. La visión que se tiene sobre los afectos recurren a las nociones de enfermedad y de peligrosidad para caracterizar a las emociones que no resultan "positivas", entendiendo por estas a las que le permitan al sujeto adaptarse a un entorno social inseguro, injusto e incierto. Las críticas que la autora dirige a la obra de

\footnotetext{
${ }^{1}$ No resulta sorprendente que la entrevista se encuentre en la sección de "salud y bienestar" del suplemento digital EntreMujeres, dado el doble movimiento de patologización y feminización de las emociones. Disponible en:https://www.clarin.com/entremujeres/hogar-y-familia/-inteligenciaemocional-escuelas-educar sentimos 0 -NJgGg1r.html

${ }^{2}$ Dra. En Cs. Sociales (UBA), coordinadora del Núcleo de Estudios Sociales sobre la intimidad, los afectos y las emociones (FLACSO).
} 
Abril 2021.

ISSN 2344-9934

Malaisi son, esencialmente, tres: lo que este entiende por emoción, la separación emoción-razón y la asociación emoción-educación moral.

En primer lugar, desde la educación emocional se caracteriza a las emociones como autoevidentes, transparentes, punto cero de la verdad del sujeto, buenas per se. En su libro Como ayudar a los niños de hoy Lucas Malaisi aconseja:

Cuando estés perdido, cerrá los ojos y el camino aparecerá. Porque el camino hacia lo que amamos está señalizado en nuestro interior (...) Las emociones jamás mienten, son una verdadera y auténtica fuente de información, tanto para nosotros mismos como para los demás, dado que no podemos esconderlas con gran facilidad (...) Para mí ellas son lo más natural y puro que tenemos, muestra genuina de quienes somos (citado por Abramowski, 2017: 257).

Hacia el final del siglo XX y fuertemente en la primera década del siglo XXI hubo una extensa producción académica preocupada por la investigación acerca de los afectos y las emociones, conocida como giro afectivo en las ciencias sociales. Esta producción académica en gran medida se interesó en la distinción conceptual entre emoción y afecto. Mientras la primera serviría para nombrar un fenómeno que ocurre en el interior del sujeto y que tiende a expresarse en el exterior, el afecto indicaría un fenómeno de relación (exterior) que es capaz de operar un cambio en el sujeto (Flatley, 2008: 21). Esta distinción resulta relevante en la medida que Malaisi parece reducir ambas dimensiones de la vida emocional-afectiva a la dimensión emocional. A su vez, concibe a la emoción como algo simple y accesible a la conciencia del sujeto, contradiciendo así los principios fundamentales de la sociología de las emociones al negar el contexto de producción en el que la emoción se inscribe:

Los aportes de la sociología de las emociones han mostrado que [las emociones] y la afectividad constituyen esa encarnación personal de una experiencia de origen profundamente social, al derivar de la relación que el yo establece con los otros y con su entorno (Nobile, 2017: 27).

Con todo, este recurso teórico le permite a Malaisi objetivar la vida interior del sujeto y convertirla en contenido disciplinar con fuertes implicancias políticas. Este objeto-emoción será nombrado con el léxico proveniente de la economía: habilidad/competencia. De este modo, se concibe a la EE como enseñanza de estas 
habilidades/competencias emocionales porque: "se basa en la transmisión de conocimiento y en la corrección de lo erróneo, como los comportamientos agresivos, impulsivos o desadaptativos en general" (Malaisi, citado por Abramowski, 2017: 257). Este objetivo sirve a dos de los pilares de la $E E$, el autoconocimiento y la autorregulación. Esta propuesta pedagógica recomienda actividades, por ejemplo, en la que los alumnos deben dividir su día en periodos (tiempos de desayuno/escuela/almuerzo/deportes/salidas/cena, etc.) y registrar su "estado emocional" al inicio de cada actividad para tener un historial semanal de los emociones experimentadas en función de lo cual realizar cambios, ejercicios de respiración, etc. (Abramowski, 2018). Por una parte, como más arriba señalábamos, uno de los dispositivos para asegurar el sujeto es el cuidado de sí, la vuelta sobre su "sí mismo" y los mecanismos de subjetividad en clave de "intensificación de la relación con uno mismo por la cual uno se constituye como sujeto de sus actos" (Foucault, 2008b: 47). En este sentido, la EE serviría como uno de estos dispositivos.

En esta misma línea, podría decirse que el pilar de la motivación es entendido en clave de autogeneración y éxito personal. Según esto, la persona sólo saldría de la esfera del yo para adquirir habilidades sociales, es decir, conocer las emociones de los otros con un fin pragmático, utilizarlas a mi favor "si buscamos un aumento de salario, más vale que se lo solicitemos al jefe un día en que está de buen humor" (Malaisi, citado por Abramowski, 2017: 266). De este modo la EE produciría sujetos recluidos en sus interioridades, preocupados por sus necesidades individuales y por su bienestar, por encima del compromiso con la sociedad y con otras personas.

En segundo lugar, el concepto de inteligencia emocional escinde la emoción de la razón. Esto permite a la EE dos prácticas: la confesión (como la actividad docente apuntada arriba) y la posterior transformación. La jerarquización de la razón por sobre la emoción, además, vuelve aceptable o más bien necesaria dicha transformación. En palabras de la autora: "en la propuesta de Malaisi no hay lugar para los escapes, ni para los sentires precarios, feos, contingentes, ambiguos, subversivos, extraños" (Abramowski, 2017: 268). Por un lado, entendidas así, las emociones feas, improductivas, deben ser cambiadas. Para ello es necesario hacer dos movimientos: 
Abril 2021.

ISSN 2344-9934

separar al sujeto de la emoción que experimenta (Gillies, 2011) y disociar la emoción de su contexto de producción (Abramowski, 2017). En el contexto anglosajón se entiende como necesaria para "alfabetización" emocional el aislamiento pero también la expresión y la posibilidad de transformación de la emoción:

El término "emotional literacy" [alfabetización emocional] implica que los estudiantes deberán ser capaces de leer y hablar con fluidez sus emociones en el aula en lugar de sucumbir ante ellas. En el proceso de "ponerse en contacto con sus emociones" y "expresarlas" los sentimientos en sí mismos deben ser puestos a distancia, bajo examen y abiertos a modificaciones (Gillies, 2011: 187, la traducción es nuestra).

La distancia entre el sujeto y sus emociones debe ser tal que tendrá que aprender a hablarlas como a una lengua extranjera. Este punto presenta también familiaridad con Foucault, en tanto que este concibe al cuidado de sí como "la insistencia en la atención que conviene concederse a uno mismo; es la modalidad, la amplitud, la permanencia, la exactitud de la vigilancia lo que se pide; es la inquietud a propósito de todas las perturbaciones del cuerpo y del alma lo que hay que evitar" (Foucault, 2008b: 47).

Por otro lado, la disociación de la emoción de su contexto de producción despoja a las emociones de todo contenido potencialmente transformador en el plano social, ya que en los lineamientos de la EE "no hay discurso pedagógico que aborde el miedo, la violencia, las adversidades y el racismo que atraviesan las vidas de los estudiantes" (Gillies, 2011: 194). Val Gillies realizó una investigación en escuelas desfavorecidas de Londres, en las que la mayoría de la población estudiantil pertenece a minorías racializadas. En su estudio de campo relata una actividad de EE en la que, por ejemplo, un estudiante negro expresó ira ante la amplia cobertura mediática del secuestro de una niña blanca de clase alta. El estudiante adujo que si se tratase de él, un adolescente "negro y pobre", no habría tanto "alboroto". De forma correctiva, la docente respondió que probablemente tenga razón, sin embargo debe sentir empatía por la niña y su situación. De este modo, la intervención docente tiene un sentido normalizador de los sentires sin tener en cuenta el contexto de injusticia y racismo en el que surge la ira, también omite el hecho de que toda emoción es particular, no toda 
ira es igual, debe ser puesta en contexto y ser interpretada desde el sujeto que la experimenta. Además, con esa práctica correctiva se insinúa que la empatía (uno de los pilares de la EE) se logra desprendiéndose de la propia emoción y situación social, en lugar de acoger en el interior de uno a la alteridad. Es decir, las emociones pierden su complejidad originaria y sufren un proceso de estandarización.

Por último, Abramowski advierte que la lógica detrás de la selección de emociones comunicables, favorables, productivas, positivas, aceptables socialmente, llevada a cabo por la EE no hace más que reflotar ciertos tópicos de la tradición pedagógica positivista argentina. Según la autora, en la escuela argentina de finales del siglo XIX, "distintas tradiciones teóricas y filosóficas se articularon de modos peculiares en pos de dejar atrás prácticas y métodos considerados vetustos, entre otras cosas, por desatender los renovados conocimientos científicos de la naturaleza infantil" (Abramowski, 2017: 262). Cabe aquí la mención, con ánimo de trazar un paralelismo histórico, de que la retórica de la EE se presenta muchas veces unida o como aplicación pedagógica de los conocimientos obtenidos en las últimas décadas en el área de las neurociencias.

Ya a finales del siglo XIX aquellas nuevas perspectivas pedagógicas se mezclaron con teorías criminalísticas y lombrosianas de la época que unían causalmente las características físicas, socio-económicas y biológicas de una persona con las probabilidades de caer en criminalidad, la maldad y la amoralidad. En nuestra época, es difícil no ver la misma operación de unión, esta vez, de emociones improductivas/indeseadas con patologías psicológicas. Según la autora "en este contexto se producen diagnósticos comportamentales -muchos de ellos de dudosa procedencia y fundamentación- que tienen por finalidad categorizar a los chicos como vulnerables, frágiles, ansiosos, hiperactivos, con baja autoestima, etc." (Abramowski, 2017: 256). Entonces, la emocionalización de la educación en primer lugar se encarga de crear los diagnósticos y luego de proponer la cura: la EE. Ésta crea una narrativa terapéutica que se nutre de una promesa: la de la felicidad. Una felicidad mensurable, definida en otras instancias distintas del sujeto y funcionales a ellas, prefabricada y considerada fundante de una vida moral. 
Abril 2021.

Si algo es bueno nos sentimos bien. Si algo es malo, nos sentimos mal. La ciencia de la felicidad se apoya en un modelo de subjetividad en el que uno efectivamente conoce como se siente y es posible trazar una distinción certera entre los buenos y malos sentimientos. $Y$ esto se toma como base del bienestar social (Ahmed, 2019: 7).

Retomando las nociones de Foucault sobre los dispositivos de seguridad, podría decirse que la Educación Emocional posee un mecanismo que regula la circulación de emociones en el espacio público, determina qué emociones son enunciables y cuáles deben ser relegadas a la intimidad del sujeto. En este sentido, Gillies relata cómo en un taller de EE una docente se siente fuertemente inhibida por los pormenores de la vida familiar que sus alumnas no temen contar en público, en consecuencia, la docente prohíbe hablar de ciertos temas en esos talleres. La autora señala que:

Sólo ciertas formas de expresión de las emociones eran sancionadas, y estas eran cuidadosamente monitoreadas por la docente. Si los límites se cruzaban (lo que pasaba a menudo) la situación era utilizada para marcar lo inoportuno de ciertos sentimientos o pensamientos, y se intentaba obtener una respuesta más adecuada (Gillies, 2011: 192).

Por otra parte, la EE pretende lidiar con lo eventual/aleatorio mediante prácticas de autoconocimiento y autorregulación. Esta propuesta pedagógica, al trabajar con el detalle de los alumnos, los individualiza, se encuentra fuertemente marcada por la lógica disciplinaria. Pero los individuos son instrumentalizados para lograr efectos a nivel población (felicidad, bienestar, salud mental, etc.). Es por ello que también podríamos considerar la EE como formando parte de los dispositivos de seguridad.

Además, también posee mecanismos de normalización en cuanto que existe una política de selección de las emociones-objeto-contenido de la intervención docente que tienen como criterio la valoración de emociones positivas como "normales". La EE erige como norma la felicidad, positividad, el autocuidado, la productividad, el éxito personal. Todo lo que difiere sufre un proceso de patologización. 
Por último, las prácticas de la EE tienen como objetivo a la población, ya que están orquestadas por el sector estatal, conforma el sistema jurídico y a la vez busca producir un tipo específico de ciudadano:

La atención de los funcionarios públicos se ha alejado de los problemas estructurales y se han concentrado en el desarrollo de las habilidades personales y el auto-mejoramiento. Desde esta perspectiva, el Estado debe facilitar la producción de ciudadanos autogestivos, empoderados, éticamente responsables y emocionalmente competentes (Gillies, 2011: 186).

Es así que el sujeto de la EE, al igual que el de los poderes disciplinario y biopolítico, no es una realidad sustancial fundante, sino un efecto de ciertas prácticas de autorregulación. Estas prácticas incluyen la atención sobre el yo para lograr la regulación de las emociones que se traduciría en éxito personal pero también en bienestar social.

Por todo ello, es necesario pensar a la EE como un dispositivo biopolítico destinado a producir sujetos "emprendedores, endeudados y felices" (Nobile, 2017). Se trata de una captura de la subjetividad vehiculizada por los mecanismos de seguridad tal como los describió Foucault, en los que se intenta regular las circulaciones para asegurar la higiene (salud emocional), se alienta el autoconocimiento en pos de la racionalización de la vida afectivo-emocional y la instrumentalización de la alteridad, se normaliza dicha vida erigiendo como normal a la positividad en detrimento de la complejidad, y se intenta producir ciudadanos dóciles, funcionales al sistema productivo, despojados de toda agencia, con una interioridad estandarizada y sin potencial de transformación social.

\section{Conclusión}

En el contexto actual de avances a nivel mundial del poder neoliberal resulta necesario llevar a cabo una reflexión sobre los mecanismos aseguradores de ese orden político para así tramar líneas de fuga posibles. Mediante la emocionalización de la sociedad el sistema busca producir sujetos autorregulados que no representen riesgos ni amenazas. La educación emocional sirve a ese propósito apelando al sentido común de la población ya que exaltar las emociones, humanizar a las personas en un contexto 
de caída de los valores, no podría ser malo a primera vista. Pero gracias a la caja de herramientas foucaultianas es posible poner en tela de juicio esta propuesta pedagógica y pensarla como un mecanismo asegurador no sólo de un sujeto, sino de un horizonte de experiencias ya no humanas sino estandarizadas, que viene a cubrir las necesidades de gobierno de un determinado orden socio-político.

Para ello resultó necesario describir en extenso las características señaladas por Foucault acerca de los mecanismos de seguridad que expresan la preeminencia en la sociedad contemporánea de la biopolítica. Esta nueva forma de gobierno surge a mediados del siglo XVIII como respuesta a la necesidad de compensar los desequilibrios presentes en la lógica del poder soberano. Este sólo podía ejercer el poder de muerte y en cuanto a la vida se limitaba a un no-hacer. Por ello el ingreso de la vida al campo de intervención posible de la política y la economía dio como resultado la creación de nociones como peligro biológico, gobierno, seguridad, población.

En este punto creemos que la educación emocional puede ser catalogada como un mecanismo regularizador ya que, como se vio, propone una estricta vigilancia de los contenidos que pueden o deben circular en el espacio público. No todas las emociones son objeto de enseñanza, sólo aquellas juzgadas como moralmente aceptables o productivas. Además, las técnicas de autoconocimiento y autorregulación ponen de manifiesto la necesidad de reconocer los "estados emocionales" para luego intervenir racionalmente sobre ellos. Esta racionalización en ocasiones implica un trabajo sobre el sí mismo pero en otras, como lo señala Gillies (2011), implica dejar circular las emociones y que sea la presión social la que actúe como reguladora de los afectos inexpresables. De este modo, la normalización es llevada a cabo mediante, por un lado, la calificación como normal de las emociones que sean productivas, y por otro a través de la moralización de la vida emocional. Por último, la EE produce una población en tanto que tiene como fin educar las emociones, es decir, producir un tipo específico de sujeto-ciudadano competente emocionalmente, vale decir: productivo. Desde los estudios sobre afectos y emociones podemos decir que esta propuesta pedagógica 
busca reducir la vida emocional-afectiva, las dimensiones subjetivas e intersubjetivas, a una pura emocionalización, a sus aspectos individuales.

Como en otras tecnologías de poder, en la EE se entrecruzan mecanismos de regulación y de disciplinamiento. La disciplina sale a la luz cuando pensamos en las dimensiones individualizantes de esta tecnología en particular. En ella conviven tensiones entre la regulación de la población, interesada en asegurar el bienestar social respecto de la "salud emocional", y la producción de individualidades característica del orden político al que la EE es funcional. Según Foucault esta paradoja es propia del poder pastoral, en él se puede señalar la necesidad de gobernar a la multiplicidad y al mismo tiempo a los individuos. Este dispositivo pedagógico posee rasgos pastorales en tanto que es esencial a su lógica la noción de "gobierno de sí". Como se dijo, la EE opera sobre las bases teóricas de dos mentes, una racional y otra sintiente, la primera jerárquicamente superior debe ser entrenada en la identificación (confesión), examen y sanción (regulación) de los productos de la segunda.

De este modo las emociones son despojadas de toda su complejidad, ya no son entendidas como un signo producido en un entorno social, político y económico sino como fenómenos potencialmente desfavorables y por ello peligrosos. En una entrevista del 2011 para la televisión española el psicólogo Claudio Naranjo ${ }^{3}$ se refirió a la EE de la siguiente forma:

La gente llega ya dañada a la escuela, llega gritona, llorona, rabiosa o malhumorada porque [la negatividad] es una peste que se transmite a través de las generaciones, de padres a hijos, es un mal, como una plaga emocional que la educación tendría la posibilidad de detener.

Es así que la riqueza de la vida emocional es vista como una amenaza, como un peligro biológico que debe ser neutralizado mediante la educación de las emociones. La tarea pedagógica de la escuela ya no es concebida como medio para conseguir la emancipación de los pueblos sino como un dispositivo que propicia la adaptación de

\footnotetext{
${ }^{3}$ Fue un médico chileno formado en psicología en EEUU, especialista en terapia gestáltica y fundador de la psicología transpersonal. Desde los noventa sus perspectivas sobre la necesidad de una reforma educativa fue adoptada por varios países, propuso una educación integral que incluyese lo que él llamaba "educación espiritual". Entrevista disponible en:

https://www.youtube.com/watch?v=1wYLhop515o
} 
Abril 2021.

ISSN 2344-9934

los sujetos al sistema de producción sin ninguna actitud crítica, creyendo con eso que el éxito personal redundará en bienestar colectivo. Además, junto con Ana Abramowski podemos afirmar que la EE representa un reflote de la educación moralizante de finales del siglo XIX, así como una estatización de las emociones, una intervención al interior de la vida más íntima del sujeto como forma de producir una población para el siglo XXI.

La escuela argentina tiene una larga tradición de resistencia hacia cualquier clase de reforma o innovación que altere las concepciones básicas acerca de la tarea educativa, sin embargo, también es alarmante la fervorosa acogida que este dispositivo pedagógico tiene en varios ámbitos. Conjeturamos que esto se debe a la apelación a concepciones hondamente arraigadas en los docentes argentinos respecto de la fuerte carga afectivo-emocional que implica la tarea de educar y que recorren las instituciones y las relaciones docente-alumnos. En este sentido, es posible señalar que la escuela siempre tuvo en cuenta las emociones y que las tradiciones pedagógicas del siglo XX están fuertemente atravesadas por la contemplación de las emociones de los alumnos, conservando toda su complejidad. Por todo ello resulta acuciante el abordaje crítico de las propuestas actuales de EE y los modos de aplicación en los distintos rincones del país. Sostenemos que ante los embates de las corrientes psicologizantes la respuesta debe hallarse en la amplia tradición pedagógica en la que la tarea llevada a cabo por la educación tiene un carácter fuertemente emancipador. 


\section{Bibliografía}

Abramowski, A. (2017). Legislar los afectos. Apuntes sobre un proyecto de ley de Educación Emocional. En A. Abramowski, \& S. Canevaro, Pensar los afectos. Aproximaciones desde las ciencias sociales y las humanidades (págs. 251-271). Los Polvorines: Universidad Nacional de General Sarmiento.

Abramowski, A. (2018). Respiración artificial. El avance de la educación emocional en la Argentina. Bordes. Revista de política, derecho y sociedad(10), 9-17.

Ahmed, S. (2019). La promesa de la felicidad. Buenos Aires: Caja Negra.

Fisher, M. (2016). Realismo capitalista. ¿No hay alternativa? Buenos Aires: Caja Negra.

Flatley, J. (2008). Affective Mapping. Melancholia and the politics of modernism. Cambridge: Harvard University Press.

Foucault, M. (1994). Hermenéutica del Sujeto. Madrid: Las Ediciones de La Piqueta.

Foucault, M. (2006a). Defender la sociedad. Curso en el Collège de France 1975-1976. Buenos Aires: Fondo de Cultura Económica.

Foucault, M. (2006b). Seguridad, territorio, población. Curso en el Collège de France 1977-1978. Buenos Aires: Fondo de Cultura Económica.

Foucault, M. (2008a). Historia de la sexualidad 2: El uso de los placeres. Buenos Aires: Siglo XXI Editores.

Foucault, M. (2008b). Historia de la sexualidad 3: La inquietud de sí. Buenos Aires: Siglo XXI Editores.

Gardner, H. (2016). La mente no escolarizada. Buenos Aires: Paidós.

Gillies, V. (2011). Social and emotional pedagogies: critiquing the new orthodoxy of emotion in classroom behaviour management. British Journal of Sociology of Education, 32(2), 185-202. doi:10.1080/01425692.2011.547305

Goleman, D. (1997). La inteligencia emocional. Buenos Aires: Javier Vergara.

Nobile, M. (2017). Sobre la educación emocional: subjetividad y psicologización en la modenidad tardía. Digithum(20), 22-33. Recuperado el 16 de enero de 2020, de http://dx.doi.org/10.7238/d.v0i20.3089

Sorondo, J. (2019). Educación emocional: nuevas formas de naturalización del discurso neoliberal. En: Actas del Congreso Internacional de Ciencias Humanas - 
Abril 2021.

ISSN 2344-9934

Humanidades Humanidades entre pasado y futuro. General San Martín: Escuela de Humanidades de la Universidad Nacional de San Martín. Obtenido de https://www.aacademica.org/1.congreso.internacional.de.ciencias.humana/26 3 